This item was submitted to Loughborough's Research Repository by the author.

Items in Figshare are protected by copyright, with all rights reserved, unless otherwise indicated.

\title{
Application of archival aerial photogrammetry to quantify climate forcing of alpine landscapes
}

PLEASE CITE THE PUBLISHED VERSION

http://dx.doi.org/10.1111/phor.12099

\section{PUBLISHER}

Wiley (Article @) The authors / Journal @ The Remote Sensing and Photogrammetry Society and John Wiley and Sons Ltd.)

\section{VERSION}

AM (Accepted Manuscript)

\section{PUBLISHER STATEMENT}

This work is made available according to the conditions of the Creative Commons Attribution-NonCommercialNoDerivatives 4.0 International (CC BY-NC-ND 4.0) licence. Full details of this licence are available at: https://creativecommons.org/licenses/by-nc-nd/4.0/

\section{LICENCE}

CC BY-NC-ND 4.0

\section{REPOSITORY RECORD}

Micheletti, Natan, Stuart N. Lane, and Jim H. Chandler. 2019. "Application of Archival Aerial Photogrammetry to Quantify Climate Forcing of Alpine Landscapes”. figshare. https://hdl.handle.net/2134/18502. 


\title{
APPLICATION OF ARCHIVAL AERIAL PHOTOGRAMMETRY TO QUANTIFY CLIMATE FORCING OF ALPINE LANDSCAPES
}

\author{
By NATAN MichELETTI (Natan.Micheletti@unil.ch), STUART. N. LANE \\ (Stuart.Lane@unil.ch), \\ Institute of Earth Surface Dynamics, University of Lausanne, Switzerland \\ JIM H. CHANDLER (j.h.chandler@lboro.ac.uk), \\ School of Civil and Building Engineering, Loughborough University, UK
}

\begin{abstract}
It is widely hypothesised that recent and future climate change may lead to landscape scale changes in geomorphic processes and process rates. However, such changes are likely to be widely distributed making their direct measurement difficult and there are almost no measurements at the decadal scale. However, aerial imagery has been acquired by many national agencies since the 1950s and significant archives remain. Unlocking the information from these data is important because it is the timescale over which significant unresolved hypotheses remain regarding the impacts of rapid climate change on Alpine environments. Application of archival aerial photogrammetry to Alpine environments is challenging because of topographic complexity (e.g. occlusion caused by sudden elevation changes, areas with large elevation ranges) and variations in image texture. Here, we describe a complete workflow from raw data to treatment of results and interpretation for such an application. We apply this to imagery for the Val d'Héréns, Switzerland, a landscape containing an assemblage of glacial, periglacial, hillslope and fluvial landforms across a height range of 1,800 to 3,600 $\mathrm{m}$ for the 1960 s to present. Even for complex and steep topography it is possible to detect changes greater than $\pm 1-1.5 \mathrm{~m}$ with the scale of imagery available (1:20,000). These changes reveal important characteristics of landscape scale erosion and deposition at the decadal scale.
\end{abstract}

KEYWORDS: Aerial photogrammetry, archival imagery, digital elevation model, geomorphology, geomorphic changes and climate forcing 
MiCHELETTI et al. Application of archival aerial photogrammetry to quantify climate forcing in high mountain landscapes

\section{INTRODUCTION}

GEOMORPHOLOGICAL research is always in need of three dimensional data to describe topographic surfaces and to monitor its change through time. The possibility of generating quantitative elevation data from stereo-photography has played an important role in this regard, as demonstrated by pioneer applications of photogrammetry to geomorphological studies (Wickens and Barton, 1971; Welch and Jordan, 1983, Small et al., 1984; Chandler and Cooper, 1988; Chandler and Moore, 1989; Lane et al., 1994). With the advent of fully automated methods and the transition from traditional to digital photogrammetry during the 1990s, photogrammetry became a widely used, cost and time effective approach for geoscience research (Lane, 2000). Crucially, it represents a unique resource for deriving three-dimensional data of past landscapes using the extensive coverage of aerial imagery commonly available since the 1950s. This type of application, named archival aerial digital photogrammetry, has proved successful for a wide range of fields, including fluvial geomorphology (Lane et al., 2003, 2010), permafrost and periglacial processes (Kääb and Vollmer, 2000; Kneisel and Kääb, 2007; Fischer et al., 2011) and hillslope processes (Chandler and Brunsden, 1995; Walstra et al., 2007; Schwab et al., 2008; Bennett et al., 2013).

Despite the ease with which elevation data can be extracted from imagery, including new photogrammetric methods like Structure from Motion (e.g. Fonstad et al., 2013), the application of digital photogrammetry for geomorphological research still poses complications. First, the ease of automated data generation offered by digital photogrammetry may cause the user to underestimate data quality issues (Cooper, 1998; Lane, 2000) or to overlook key data quality controls (James and Robson, 2014). This is problematic because in spite of the advanced algorithms and automated processes offered by digital and emerging forms of photogrammetry, conventional controls upon photogrammetric-derived data are still crucial and need careful consideration. Second, the application of aerial digital photogrammetry in areas of complex or rough topography and large elevation ranges can be problematic, particularly occlusions caused by sudden elevation changes or where the density of acquired data is low in areas of complex topography. Third, because archival aerial imagery may have been acquired at a large range of flying heights its scale may be unsuitable for generating precise elevation data within small areas. Accordingly, the limits of detectable changes need to be carefully considered to ensure correct interpretation of results. Finally, older aerial photographs can be characterized by imagery of low contrast and varying quality, which improved with time as photogrammetric emulsions evolved; data processing and the quality of final results will inevitably be affected by this variability.

Sediment production and transfer and glacial and periglacial processes in high mountain basins are potentially sensitive to the significant changes in climatic conditions that have affected the European Alps over the past century. Understanding the effects of such changing conditions upon landscapes is challenging because of the difficulty of investigating this forcing at the timescale of decades to centuries, despite this being the timescale over which significant hypotheses are raised over human impacts upon climate change and consequently 
geomorphic systems (Reynard et al., 2012; Knight and Harrison, 2013). Archival aerial imagery offers a unique opportunity to address this scientific topic (see Schwab et al., 2008; Bennett et al., 2013). The research described in this paper seeks to describe the complete workflow adopted for the application of archival aerial photogrammetry in the Swiss Alps to assess the extent to which geomorphological changes associated with climate forcing can be quantified in high mountain landscapes.

A sequence of aerial imagery from the 1960 s to present has been used to compute digital elevation models for the Val d'Héréns, Switzerland (Fig. 1). The case study consists of a steep deglaciated zone, ranging from c. 1,800 to 3,600 metres above mean sea level (m.a.s.l.). The area is comprised of an actively changing and hence locally dynamic assemblage of glacial, periglacial, hillslope and fluvial landforms. It is likely to be sensitive to climate forcing, by virtue of landforms highly sensitive to temperature changes (glaciers and permafrost) and because of the presence of unconsolidated, historically-weathered and glaciallyderived material, representing high potential for significant sediment mobilization.

In presenting the workflow, we identify the issues that arise at different stages of the data processing and propose solutions applicable even with limited ground control data. Thus, we offer guidance, advice and caveats for the potential geomorphological applications of archival aerial photogrammetry in high mountain environments. All photogrammetric data processing has been performed using ERDAS IMAGINE Leica Photogrammetriy Suite (LPS) 2010, released in November 2009, while post-processing operations and results analysis have been implemented using Matlab and ArcGIS. 
MiCHELETTI et al. Application of archival aerial photogrammetry to quantify climate forcing in high mountain landscapes

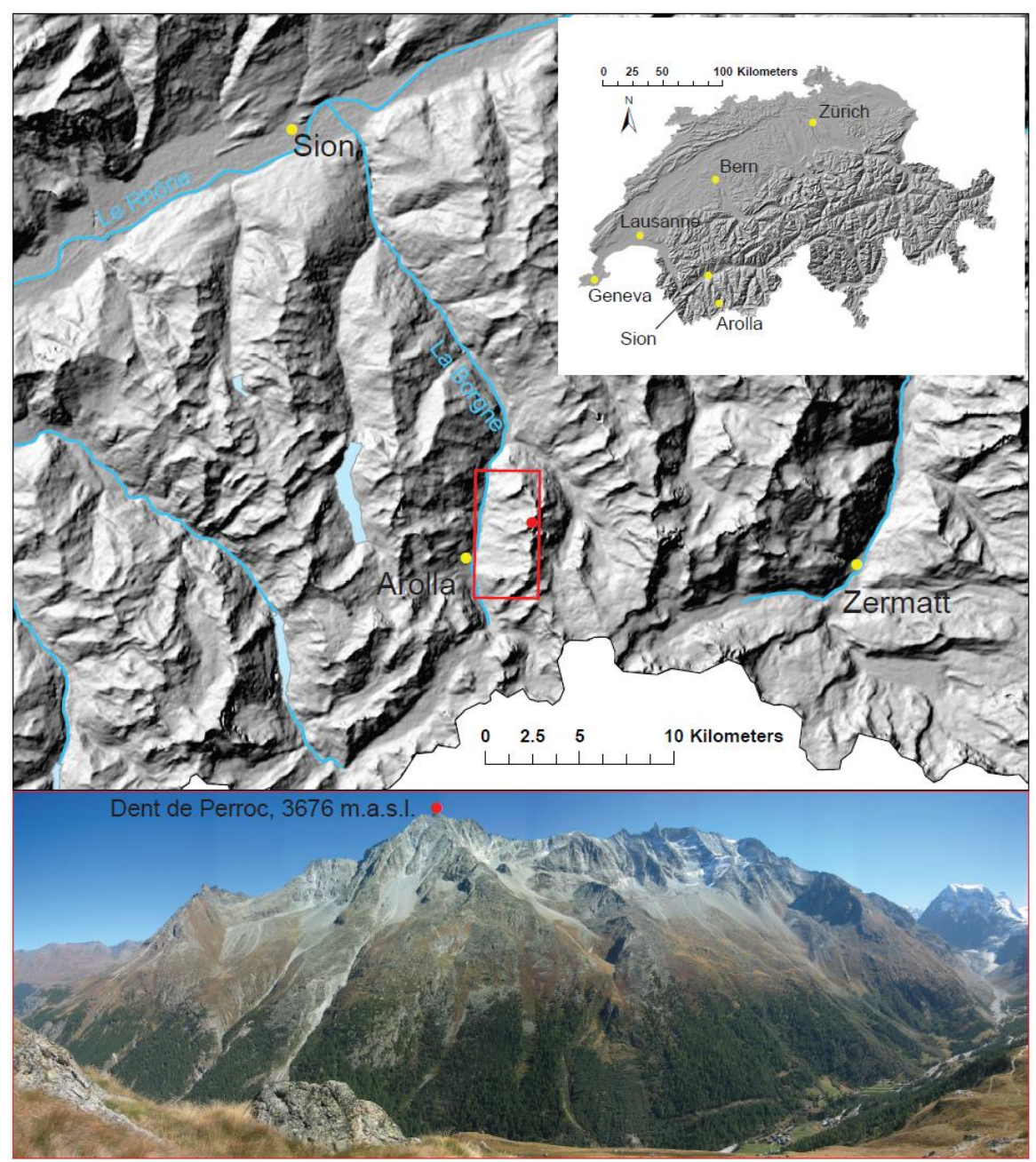

FIG 1. Case study in Arolla, Hérens Valley, Switzerland (Relief shaded and river data: Swisstopo, Photograph: Lambiel 2004)

\section{AERIAL IMAGERY AND INTERIOR ORIENTATION}

The archival aerial images used in the study were acquired by the Swiss Federal Office of Topography (Swisstopo) using a range of different analogue cameras. It includes a number of $23 \times 23 \mathrm{~cm}$ images for seven distinct epochs, all collected at similar periods of the year (end of summer - beginning of autumn) with flying heights varying between 5,000 and 7,000 m.a.s.l. These have been scanned by Swisstopo at $14 \mu \mathrm{m}$ resolution (1814 dpi) using a photogrammetric quality scanner and vary in scale between 1:15,700 and 1:28,000. The overlap between two consecutive frames in a flight line is c. $80 \%$, a routine Swisstopo policy because of the high relief displacement in such mountainous areas. 
An eighth set of aerial photographs was acquired in 2012 by Flotron AG using an UltraCam-X digital camera, which represents the most recent dataset of the study. The UltraCam-X camera is equipped with 4 panchromatic and 4 multispectral lenses. The images are composed of 14,430 x 9,420 pixels of $7.2 \mu \mathrm{m}$ (c. $10.39 \times 6.78 \mathrm{~cm}$ frame size) and have a scale of 1:5,200. The endlap specification was $80 \%$ also; therefore, 12 images were used to cover the whole area of interest. The list of images used for the study and their characteristics are presented in Table I.

TABLE I. Characteristics of the aerial imagery available (Swisstopo 2012, Flotron 2012)

\begin{tabular}{lllll}
\hline Date & Scale & Lens type & Emulsion & $\begin{array}{l}\text { Calibrated } \\
\text { focal } \\
\text { length } \\
\text { (mm) }\end{array}$ \\
\hline (1) 28.09 .1967 & $1: 15,700$ & 15 UAG 120 & BW & 152.87 \\
(2) 08.09 .1977 & $1: 20,900$ & 3008 15 UAG II & BW & 153.02 \\
(3) 19.07 .1983 & $1: 19,000$ & 15/4 UAG & BW & 153.37 \\
(3) 07.09 .1983 & $1: 20,900$ & 15/4 UAG & BW & 153.37 \\
(4) 10.08 .1988 & $1: 20,900$ & 15/4 UAG & BW & 153.37 \\
(4) 10.08 .1988 & $1: 23,500$ & 15/4 UAG & BW & 153.37 \\
(5) 07.10 .1995 & $1: 26,800$ & 15/4 UAG-S & BW & 152.52 \\
(6) 02.09 .1999 & $1: 26,000$ & 15/4 UAG-S & RGB & 152.52 \\
(6) 02.09 .1999 & $1: 28,000$ & 15/4 UAG-S & RGB & 152.52 \\
(7) 17.08 .2005 & $1: 24,600$ & 15/4 UAG-S & RGB & 153.51 \\
(7) 17.08 .2005 & $1: 24,800$ & 15/4 UAG-S & RGB & 153.51 \\
(8) 20.09 .2012 & $1: 5,200$ & UltraCamX lenses (4 & RGB-NIR & 100.50 \\
& & PAN \& 4 MS) & & \\
\hline
\end{tabular}

A block file representing each epoch was created in ERDAS LPS, using either frame or digital camera geometric models for Swisstopo and Flotron imagery respectively and employing the Swiss coordinate system with the geodetic datum CH1903. Calibration certificates were available at www.swisstopo.admin.ch. This resource provided: (i) the calibrated focal length; (ii) radial distortions referenced to the principal point of symmetry (PPS); (iii) principal point of symmetry (PPS) displacement with respect to the focal centre (FC); and, (iv) fiducial mark coordinates referred to the FC. To complete the definition of the internal geometry of the camera, fiducial marks were manually measured on the images and a $2 \mathrm{D}$ affine transformation established to determine the origin of the photo coordinate system (Intergraph Corporation, 2014). This transformation was achieved with a sub-pixel RMSE, typical for this type of imagery. 
MiCHELETTI et al. Application of archival aerial photogrammetry to quantify climate forcing in high mountain landscapes

The Flotron AG digital imagery was provided with a calibration file for the digital camera. This provided the calibrated focal length $(100.5 \mathrm{~mm})$ and the PPA offsets. Imagery was corrected by Flotron AG to show no significant radial distortions. Calibrated fiducial marks and associated management were not necessary because the photo coordinate system can be defined simply by indicating the pixel dimensions $(7.2 \times 7.2 \mu \mathrm{m})$ in ERDAS LPS.

\section{FIELD DATA AND EXTERIOR ORIENTATION}

Considerable fieldwork was required to establish an appropriate number of ground control points (GCPs) necessary for photogrammetric restitution and the unstable high mountain environment creates significant challenges. The GCPs need to satisfy a range of requirements: (i) stable in time (that is, not moving or changing in appearance during the period of study), and (ii) easily and precisely identifiable on the images. Finding sufficient points with these characteristics can be problematic in an active landscape where some areas are typically: difficult to access; may or may not be experiencing movement over a 50 year period; or are devoid of infrastructure. Ideal candidates for this kind of study are the corners of the roofs of traditional and un-renovated buildings, but use had to be made of the centre of medium size, round shaped boulders (approximately $2 \mathrm{~m}$ of diameter given the scale and resolution of imagery) isolated and located in clearly stable areas. Such boulders were preferred because they can be easily identified on images and the uncertainty when measuring their apparent centre is limited. It is also fundamental that points provide adequate coverage across the site, including a wide elevation range.

Two Leica System 500 differential GPS units were used to obtain the required control for the case study, the field campaign being carried out in July 2012. A total of 169 GCPs were measured along the valley bottom and mountainsides, across an area of approximately $20 \mathrm{~km}^{2}(3 \times 6.5 \mathrm{~km})$ and with an elevation range of more than $1,000 \mathrm{~m}$ (1,808 to 2,828 m.a.s.1.) (Fig. 2). A dGPS base station was established early in the field programme and six hours of static observations obtained. Data were subsequently downloaded from the nearest available Automated GNSS Network for Switzerland (AGNES) located in Martigny, $30 \mathrm{~km}$ away in the Rhône valley. These were post processed in Leica Geo Office to correct coordinates to the Swiss national coordinate system CH1903. Visual inspection of the horizontal displacement derived by the correction using Swisstopo orthophotos is shown in Fig. 3. It was not possible to survey all the points using a single base because of limits in radio communication, either because of base-rover distance or topographic screening. Three further base stations were established in the valley, all linked directly to the initial base station. Subsequent post-processing of the original RTK data allowed determination of coordinates of all GCPs in the CH1903 system. All GCP coordinates were estimated with a precision better than $\pm 0.05 \mathrm{~m}$. 
MiCHELETTI $e$ t al. Application of archival aerial photogrammetry to quantify climate forcing in high mountain landscapes

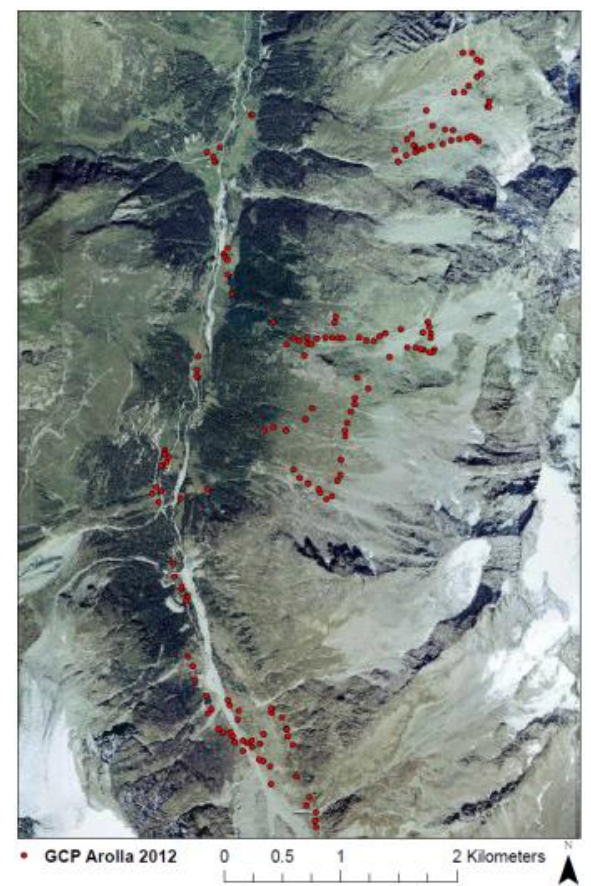

FIG 2. Ground Control Points distribution in the Arolla Valley, Switzerland

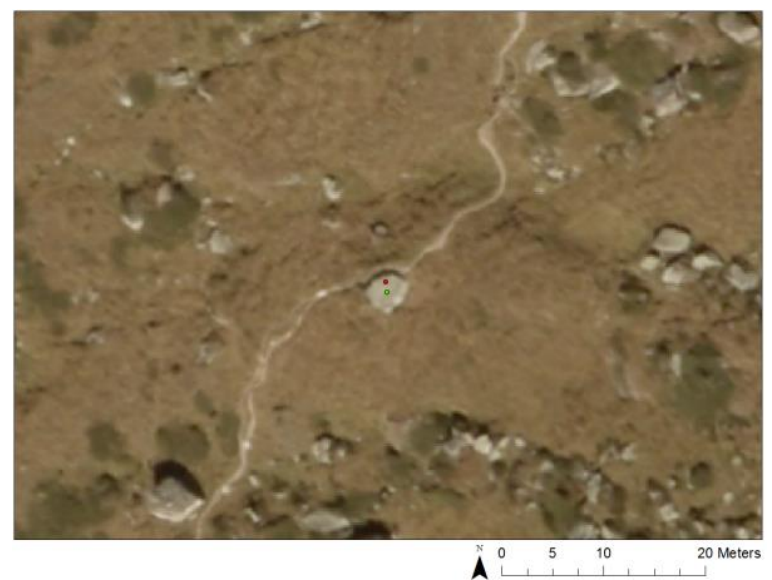

FIG 3. Ground Control Points prior (red) and post (green) post-processing correction using Swiss Automated GNSS Network data. The point, located in a stable area near a path, was measured at the centre of the boulder, but it was necessary to correct the newly established dGPS base to derive correct coordinates. 
MiCHELETTI et al. Application of archival aerial photogrammetry to quantify climate forcing in high mountain landscapes

To estimate initial exterior orientation parameters associated with each image, the GCPs were manually measured and assigned to the corresponding point on the images. It was not necessary to measure all GCPs, and neither could every GCP be found or identified precisely. The availability of a large dataset of GCPs reduced the reliance upon individually measured points, hence improving the quality of the solution. After having identified a sufficient number of control points, well distributed in space and with a large elevation range, a proportion were reclassified as check points. Check points are not used to estimate the exterior orientation parameters but to provide a direct estimate of the accuracy of the restitution. This is done in terms of discrepancy to the GCP coordinates.

After solving the initial bundle adjustment using just GCP measurements, it was possible to perform automatic tie point extraction. However, and as mentioned in similar studies (see Fischer et al., 2011), this procedure is not efficient for areas including extremely steep terrain and exhibiting many shadows. Therefore, either automatically-generated tie points needed to be checked manually or tie points measured manually. An additional problem arose during the processing of Flotron AG 2012 imagery. GCPs could not be surveyed in all parts of the mountainside because of dangerous and difficult access in the region of cliffs. This was problematic since, given the large scale of 2012 images, there were insufficient number of control points for some frames and LPS (and traditional photogrammetric packages) requires a sufficient number of GCPs for successful solution of the bundle adjustment. To address this issue, a wellestablished ground control point transfer procedure was adopted (see Lane et al., 2010). First, a bundle adjustment was obtained for those images where sufficient GCPs were available. Second, on these images, clearly identifiable features were found and marked as common tie points where they were also visible on images without sufficient GCPs. Third, these tie points were relabelled as GCPs and were measured on the images without sufficient GCPs and the measurements used to obtain a bundle adjustment for all of the imagery. As explained in Lane et al. (2010), it is important to note that these new ground control points have poorer precision than those regularly surveyed directly in the field using dGPS. However, this approach provided a viable and satisfying solution for images with insufficient GCPs.

ERDAS LPS uses a conventional bundle adjustment to perform the aerial triangulation and to estimate exterior orientation parameters for each image used (Intergraph Corporation, 2014). In this procedure, image point and GCP standard deviations are crucial and need to be commensurate with the expected precision of both image measurements and object control. This allows for more flexibility during the bundle adjustment and leads to a better solution. Image point standard deviation can be indicated in pixel units and should be related to measurement precision and image quality/resolution. These values were changed to 0.5 for the scanned Swisstopo imagery, whilst the default value of 0.3 was used for the digital Flotron AG 2012 imagery. GCPs were constrained to an object precision of $0.5 \mathrm{~m}$ in plan and $0.3 \mathrm{~m}$ in height. These globally applied values were chosen to account for the following uncertainty sources: (i) imprecision in measuring the centres of boulders or in surveying non-horizontal boulders in steep zones; and (ii) 
uncertainty in dGPS measurements themselves, including post-processing with AGNES data.

ERDAS LPS offers a number of indicators to estimate the quality of the exterior orientation solution. The Total Image Unit-Weight (TIUW) RMSE is a global precision indicator describing the quality of the entire solution in the image space (Intergraph Corporation, 2014). Root mean square errors for both control and check points are also provided, and for both ground coordinates XYZ and stereo intersection accuracy in image coordinates xy (Fischer et al., 2011, Intergraph Corporation, 2014). The aerial triangulation summary for each epoch is presented in Table II. Overall, the bundle adjustment yielded very satisfying results and in accordance with what was expected assuming the known data quality. This is of fundamental importance because it is has been shown that random error in a bundle adjustment can translate into systematic error in the stereo-matching derived data (e.g. Lane et al. 2004), and so effort is required to minimize them. These data also give a preliminary indication of the possible precision of data points extracted from the imagery although, as we discuss below, this may be downgraded according to the success of the stereo-matching process.

TABLE II. Exterior orientation performances (XYZ in meters, xy in pixels)

\begin{tabular}{llllllllllll}
\hline Year & TIUW & \multicolumn{4}{c}{ Control point RMSE } & \multicolumn{6}{c}{ Check points RMSE } \\
& RMSE & $\mathrm{X}$ & $\mathrm{Y}$ & $\mathrm{Z}$ & $\mathrm{x}$ & $\mathrm{y}$ & $\mathrm{X}$ & $\mathrm{Y}$ & $\mathrm{Z}$ & $\mathrm{x}$ & $\mathrm{y}$ \\
\hline 1967 & 0.41 & 0.46 & 0.43 & 0.15 & 0.31 & 0.31 & 0.42 & 0.23 & 0.26 & 0.07 & 0.11 \\
\hline 1977 & 0.30 & 0.28 & 0.28 & 0.14 & 0.29 & 0.30 & 0.41 & 0.07 & 0.18 & 0.32 & 0.01 \\
\hline $\begin{array}{l}1983 \\
\text { (July) }\end{array}$ & 0.32 & 0.23 & 0.29 & 0.14 & 0.41 & 0.33 & 0.15 & 0.45 & 0.44 & 0.24 & 0.09 \\
\hline $\begin{array}{l}1983 \\
\text { (Sept) }\end{array}$ & 0.31 & 0.30 & 0.27 & 0.10 & 0.29 & 0.30 & 0.45 & 0.15 & 0.43 & 0.21 & 0.08 \\
\hline 1988 & 0.33 & 0.41 & 0.45 & 0.26 & 0.44 & 0.35 & 0.36 & 0.30 & 0.45 & 0.21 & 0.39 \\
\hline 1995 & 0.29 & 0.29 & 0.37 & 0.19 & 0.32 & 0.25 & 0.09 & 0.29 & 0.56 & 0.28 & 0.18 \\
\hline 1999 & 0.36 & 0.30 & 0.31 & 0.22 & 0.35 & 0.30 & 0.38 & 0.33 & 0.38 & 0.25 & 0.20 \\
\hline 2005 & 0.34 & 0.22 & 0.28 & 0.17 & 0.28 & 0.33 & 0.25 & 0.27 & 0.38 & 0.26 & 0.21 \\
\hline 2012 & 0.17 & 0.12 & 0.13 & 0.14 & 0.17 & 0.19 & 0.28 & 0.24 & 0.18 & 0.14 & 0.22 \\
\hline
\end{tabular}

\section{AUTOMATIC STEREO-MATCHING}

In digital photogrammetry, automatic stereo-matching algorithms are used to identify homologous point pairs and to compute their ground coordinates using exterior orientation parameters (Dissart and Jamet, 1995). These algorithms are based upon detecting similar image intensity patterns within either small image "areas" or located around distinct "features". This distinction is the basis of classifying the approaches into either feature-based or area-based (Remondino et al., 2014). Feature-based approaches achieve correspondence between interest points. These are locations which exhibit "distinctness" and identified using an interest operator, generally attributed to Förstner (1986). On the other hand, areabased methods correlate small windows of pixels on two images to perform the matching. Accordingly, crucial to the matching process is sufficient texture or variations in pixel intensity in the images (Lane et al., 2000; Remondino, 2014). In 
MiCHELETTI et al. Application of archival aerial photogrammetry to quantify climate forcing in high mountain landscapes

ERDAS LPS, two area-based stereo-matching algorithms are now available, Automated Terrain Extraction (ATE) and enhanced Automated Terrain Extraction (eATE), the latter being capable of classifying points. Both eATE and ATE were evaluated and considered but ATE required more modest computing resources and was more rapid, easier to use and hence more effective. In addition, ATE has been successfully used in the past on a range of projects (Walstra et al, 2007; Lane et al, 2010) and was therefore adopted for this study. ATE exploits the epipolar constraint to improve the image matching process and offers customizable strategy parameters for optimizing results, along with suggested parameters sets for a number of terrain types (e.g. high mountains, rolling hills, urban areas, etc.). These parameters may strongly influence coordinate determination in mountainous regions (Lane et al., 2000). Among the parameters available, the correlation coefficient limit, the correlation window size and the search window size on the epipolar line are indicated as most important (Leica Geosystems Geospatial Imaging, 2006). The correlation coefficient limit indicates the minimum acceptable correlation for two matched pixels for the point to be accepted. A high coefficient threshold inevitably identifies only high quality matches (Lane et al., 2000). It is obvious that a trade-off is necessary for this parameter; keeping only high quality matched points means that the total number matched is smaller, which can be a problem in mountainous topography where the relief can be complex. On the other hand, accepting low correlation matches can allow false matches to be included in the data set and hence produce poorer quality data. The default value for this parameter for high mountains is 0.8 (Intergraph Corporation, 2014). The correlation window size is the size in pixels of the area used for computing the correlation coefficient between sets of pixels on different images. This usually needs to be smaller for areas containing large degrees of topographic relief, grey level or color intensity variation; the default value proposed by ERDAS LPS (Intergraph Corporation, 2014) for high mountain regions is $7 \times 7$. The search window size across the epipolar line can be adapted to help the point matching in cases of low quality of the exterior orientation that is, to permit the matching of points further away from the epipolar line. Finally, the user needs to indicate the output cell size, which determines the resolution of the rasterized DEM. In this research, for reasons explained below, point clouds of ground coordinates generated from matched points and exterior orientation parameters are preferred as an output instead of an already rasterized or triangulated DEM.

We would expect the strategy parameters to affect different surface characteristics in different ways, not least because surface cover influences image texture. Thus, to assess strategy parameter effects, a very high density of check data is needed, and certainly beyond what could be acquired practicably during a normal field campaign (Lane et al., 2004). The alternative is to use sensitivity analysis where key parameters are varied one-at-a-time to quantify their effects on estimated elevations (e.g. Gooch and Chandler, 2000; Lane et al., 2000). Consequently, the effect of varying the correlation coefficient limits $(0.7-0.9)$ and correlation window sizes $(5 \times 5-11 \times 11$ pixels $)$ was quantified. The comparison of results is performed at the level of point clouds ( $\mathrm{X}, \mathrm{Y}, \mathrm{Z}$ coordinates), by associating points within a Euclidean distance of $0.5 \mathrm{~m}$ in $\mathrm{X}$ and $\mathrm{Y}$ dimensions, 
and comparing their elevation in order to assess the sensitivity of extracted data to strategy parameters. For this detailed sensitivity analysis, two pairs of images from the 1988 epoch were used. Three regions of interest (ROIs) with contrasting terrain characteristics and image texture were identified for the analysis: a field of large boulders, a zone of fine sediments and texture, and a steep area with abrupt elevation changes. Changing the correlation window or the search window sizes did not produce any change for any of the three ROIs, an outcome that can be explained by the robustness of the exterior orientation solution and the presence of sufficient texture in the images. However, modifying the correlation coefficient limit has important consequences. Increasing the coefficient from 0.7 to 0.8 causes a reduction of about $10 \%$ in the number of extracted points, while an increase from 0.8 to 0.9 only $3 \%$. This is satisfying since it indicates that using the suggested value for high mountain environments (0.8) provides good quality output. Furthermore, changing the correlation coefficient also caused elevation changes to some points (Table IV). These differences have an expectation $(\mu)$ and a median $\left(\mathrm{Q}_{.50}\right)$ of zero for each ROI; although, the degree of spread varies. To help interpret the distribution of elevation differences, the cumulated distribution of the absolute elevation discrepancies is shown in Fig. 4. The latter demonstrate that the majority of points are not sensitive to strategy parameters, as confirmed by the low value containing two-thirds of absolute residuals (the 66\% quantile in Fig. 3 corresponding to 0.17 for the fine texture zone and 0.34 for the others).
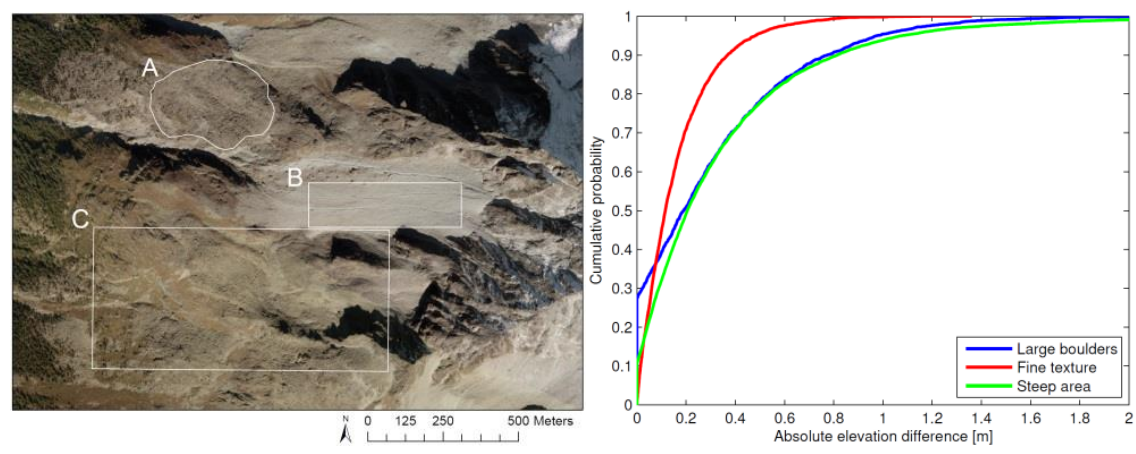

FIG 4. Effect of correlation coefficient parameter change $(0.8-0.9)$ on single points for zones of different morphology and texture (A: large boulders, B: fine texture, C: steep area).

TABLE III. Distribution statistics of elevation difference caused by correlation coefficient parameter change (0.8-0.9) on single points.

\begin{tabular}{ccccccc}
\hline ZONE & $\mu$ & $\sigma$ & $Q_{.50}$ & $\mu(a b s(d z))$ & $Q_{.50}$ of abs & $Q_{.66}$ of $a b s$ \\
\hline Boulders & 0 & 0.45 & 0 & 0.29 & 0.19 & 0.34 \\
Fine texture & 0 & 0.23 & 0 & 0.16 & 0.12 & 0.17 \\
Steep area & 0 & 0.62 & 0 & 0.34 & 0.20 & 0.34 \\
\hline
\end{tabular}



mountain landscapes

Changes in stereo-matching strategies appear to affect only some points in the generated DEM, and this justified further use of the Failure Warning Model (FWM) developed by Gooch and Chandler (2000). Gooch and Chandler (2000) employed the FWM to demonstrate that changing strategy parameters affects only less robust points in steep, low texture or shadowed areas, whilst elevation estimations of the remainder of the derived points are almost unaffected. In this study, it was used as an informative tool to define automatically areas that are susceptible to changes in the strategy parameters and thus where elevation data are unreliable. This approach is used to justify the use of the strategy parameters employed and provides an alternative to the lengthy and demanding parameter optimization process, which requires independent data.

The principle of the FWM is that the sensitivity of strategy parameters can be used to identify areas where elevation data quality are likely to be poorer and thus provide a caveat for further DEM use (Gooch and Chandler, 2000). The FWM algorithm includes two parts. In the first part, the slope in an area around interpolated points is investigated to identify unreliable interpolation estimates, particularly critical in complex or steep topographic zones. The second part consists in the identification of areas susceptible to changes in the strategy parameters using DEMs of Difference (DoD). In this stage, the value of each point in the difference image is examined individually. If that value is greater than the standard deviation of all points in the model multiplied by a user definable parameter $A$ (here $A=1$ ), the point is tagged as sensitive (Gooch and Chandler, 2000).

$$
\left|D o D_{x, y}\right|>A \cdot S T D(D o D)
$$

To continue the investigation of the effect of varying the strategy parameters on the stereo-matching procedure, the second phase of the FWM was applied here for the 1959 and 1988 epochs (Fig. 5). Results are consistent between the two years, with similar zones sensitive to strategy parameters highlighted by the model. These correspond mostly to steep, low texture or shadowed areas. In contrast, the rest of the area does not seem to be affected by changes in the strategy parameters. On this basis, the final data were processed using the suggested parameters for high mountain areas for every epoch, and the observation regarding the lower confidence of data points in relatively steep, low texture or shadowed areas was noted. A masking procedure is necessary to address issues in these areas, as explained later. 

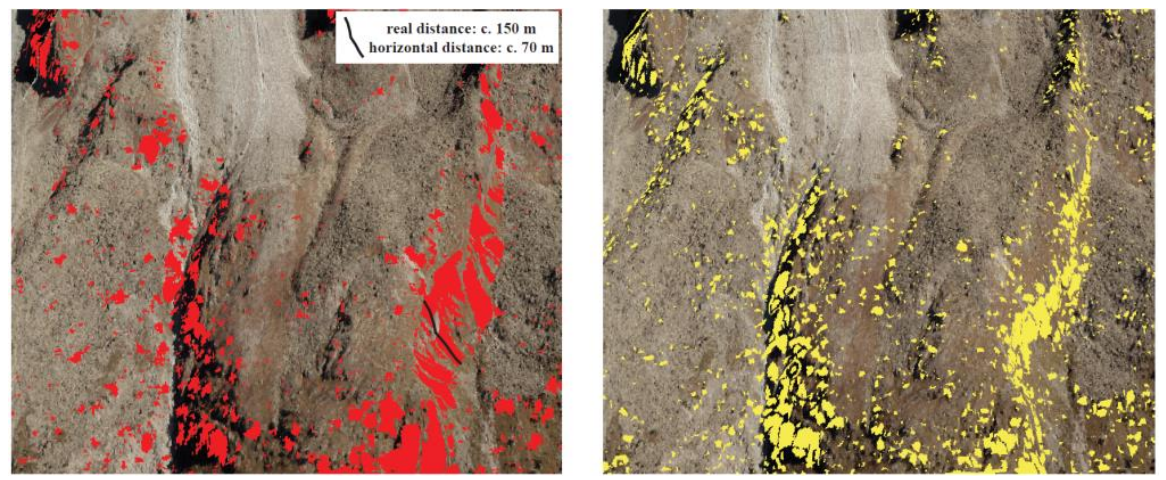

FIG 5. Example of 3D visualization of Failure Warming Model output for 1988 (red, left) and 1959 (yellow, right) imagery, generating similar results in highlighting very steep or low textured areas.

\section{DATA POST-PROCESSING}

For each image used in this research, raw point clouds of ground coordinates generated from matched points were extracted using the ATE DEM extraction module in LPS. Despite a robust bundle adjustment and stereo-matching parameters adapted to mountain regions, the derived elevation data can still present errors in the form of mismatched points that generate either negative or positive spikes. A common practice to address these issues is the application of a filter over the rasterized DEM, typically a low-pass filter, but this is known to cause loss of detail and possible propagation of error into good points (Lane et al., 2004; Milledge et al. 2009). Hence, it is preferred to adopt an approach able to identify and to remove elevations that are probably incorrect. To perform this operation, two filtering methods were adopted. The first is a statistical, Chauvenettype criterion using reliable external elevation data in the form of a coarse registration DEM (25m resolution Swisstopo DEM, 2005). Each derived elevation $z_{p}$ is evaluated as follows:

$$
\left|z_{p}-z_{c}\right|>1.96 \cdot \text { stdfilt(coarse DEM) }
$$

where $z_{p}$ is the elevation of a stereo-matching derived point, $z_{c}$ is the pixel value of the coarse DEM where the point falls into, and stdfilt(coarseDEM) is the standard deviation of elevation in the 3-by-3 neighbourhood around this pixel. This condition identifies elevations that significantly differ from the coarse DEM. By using a locally derived standard deviation, the algorithm allows for large differences in steep zones but is less permissive in flat areas. Since it relied on a 2005 DEM in this study, it is clear that the filter is not reliable where local rates of elevation change in time are high. Therefore, we used a geomorphological map 
MiCHELETTI et al. Application of archival aerial photogrammetry to quantify climate forcing in high mountain landscapes

(Maillard et al., 2013) to identify zones matching this condition, as glaciers, debris-covered glaciers, push moraines or rock glaciers. The filter was not applied in such regions.

The second method is a topographic criterion using localised slope to detect spikes. A triangulated irregular network (TIN) was generated from the point cloud and slopes higher than $50^{\circ}$ were highlighted. Points responsible for these slopes were removed and the TIN updated to deal with clusters of erroneous points. The iteration was completed three times. This method is clearly not reliable for very steep slope zones or cliffs, hence these areas were identified and removed from the analysis. The combined outcome for both methods was used to decide whether to retain or remove points, and the geomorphological map (Maillard et al., 2013) was employed to use the filter more appropriately to the local land surface. DEM error is supposed to vary with the type of surface and hence error handling procedure should be sensitive to surface type and be adaptable to ensure retention of good quality points. Further, this procedure was applied only in cases where the derived data seem to contain erroneous points in order to avoid unnecessary elimination of good quality points.

An interpolation in the GIS environment ArcGIS was performed to generate final 1 meter resolution raster DEMs using Ordinary Kriging with polynomial trend removal of order 3 and a stable variogram model. Since the derived datasets generally have high density of points, the effect of the interpolation on the result is expected to be considerably reduced. However, areas with lower densities are indeed present and very sensible to the choice of the interpolator and its parameters. In this sense, comparative analysis of interpolators is largely discussed in the literature (e.g. Aguilar et al., 2005, Arun, 2013). Where more than one image pair was necessary to cover the region of interest, mosaicking was performed in ERDAS 2010 using the overlapping function "feather". Examples of hillshades for 2012 data and for archival Swisstopo imagery are presented in Fig. 6.

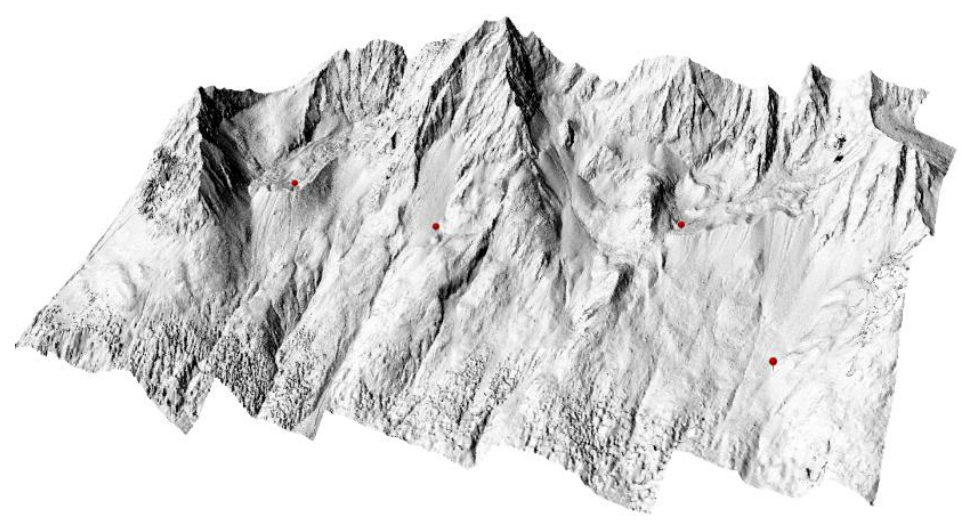




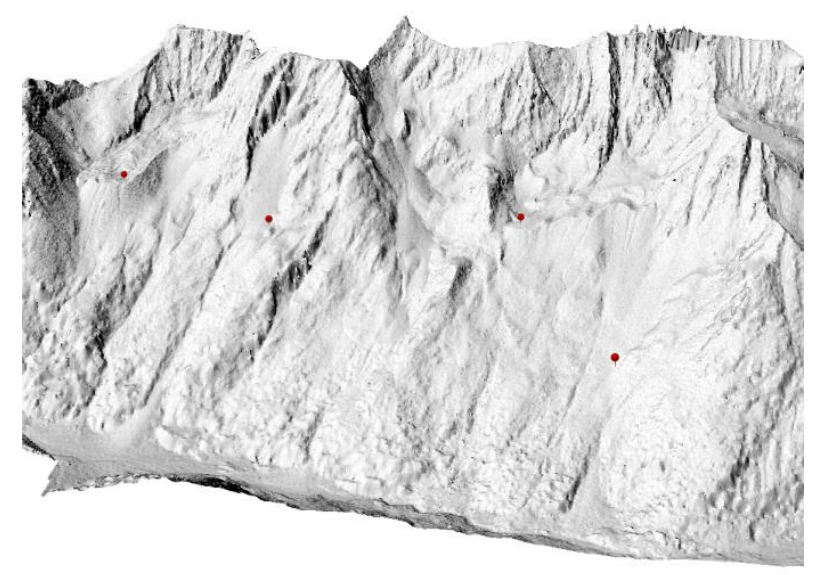

FIG 6. Examples hillshades for Flotron recent imagery (2012, above) and archival Swisstopo data (1988, below), with examples of four common points in red.

\section{QUALITY ASSESSMENT AND ERROR PROPAGATION}

The final DEMs should be evaluated to establish their quality. This may be achieved by taking datasets from different dates and comparing individual data points for zones where the use is absolutely certain that no changes have occurred (e.g. Dewez et al., 2013). In our case, we could not assume that there were zones of no change and so needed to focus upon high resolution and high quality independent data points. However, such data are not typically available in this kind of study and, thus it can be challenging to obtain a reliable estimation of the quality of a derived DEM. In this case we had a number of high quality spot measurements in the terms of unused GCPs, and these were available for quality assessment. In this analysis, we used only points on the hillslope to assess the final DEMs. As in Lane et al. (2000), the error was defined as the difference in elevation between dGPS measurement and DEM value at that location, and the error value is used to compute accuracy in the form of mean error (ME) and precision in the form of standard deviation of error (STD) as follows:

$$
S T D=\sqrt{\frac{\sum_{i=1}^{n}\left(\left(p_{i}-s_{i}\right)-\left(\overline{p_{l}-s_{l}}\right)\right)^{2}}{n}}
$$

where $p_{i}$ and $s_{i}$ are the associated photogrammetric DEM and dGPS survey elevations. Use of the ME and the STD in this way requires the errors to be Gaussian, which is often not the case in digital photogrammetric applications (Höhle and Höhle, 2009). Gaussian error allows a probabilistic confidence 
MiCHELETTI et al. Application of archival aerial photogrammetry to quantify climate forcing in high mountain landscapes

approach to the propagation of error (see below). If the errors are not Gaussian, alternative approaches are needed to estimate random error. Höhle and Höhle (2009) proposed guidelines for robust accuracy measures suited for non-normal error distribution based on quantile descriptors.

To investigate the normality of the error distribution, measured quantiles were plotted against the quantiles of a normal distribution having the same mean and standard deviation, in a QQplot, and the two cumulative distribution functions were compared (Fig. 7). Additionally, the Lillifors test was used to evaluate the null hypothesis that DEM errors are normally distributed. In every case the hypothesis was rejected at the 5\% significance level. The outcome verified that all DEMs errors distributions follow a normal distribution.
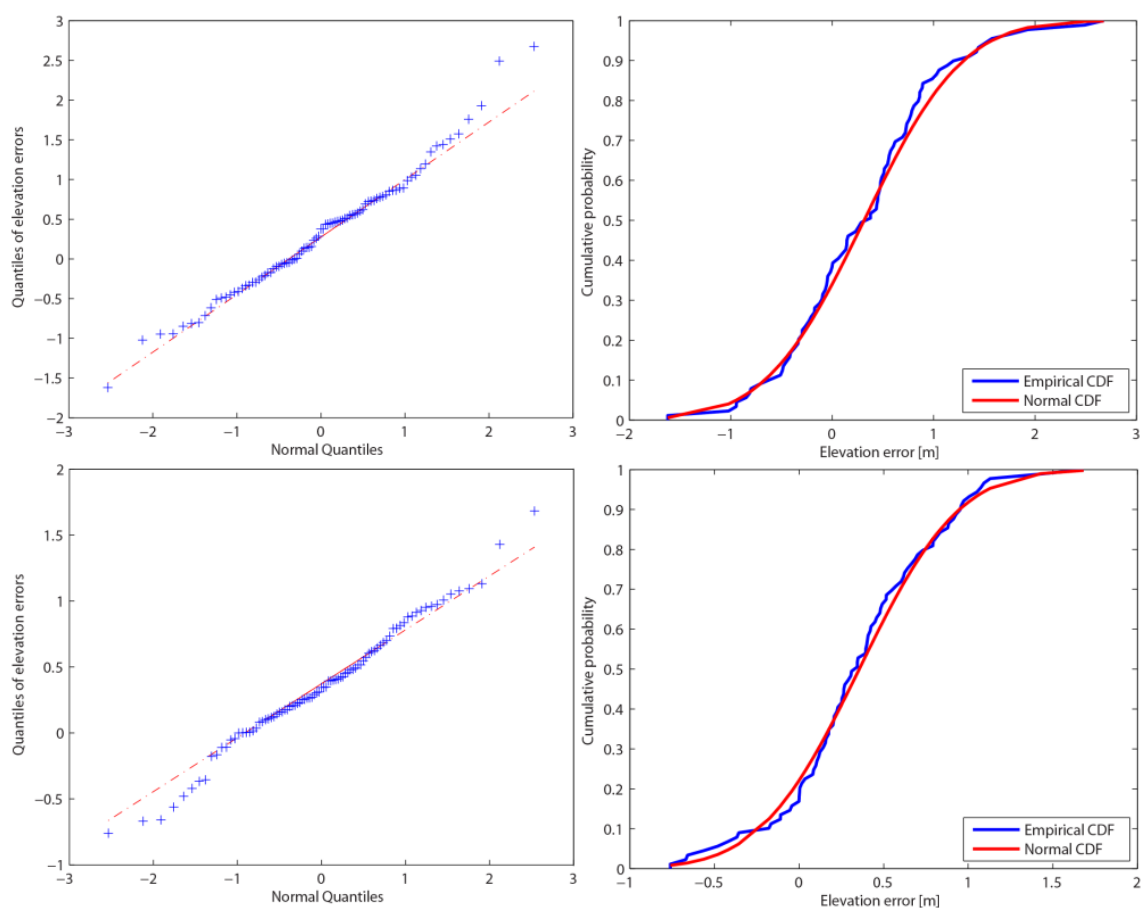

FIG 7. QQplot (left) and cumulative distribution function (right) of error data versus standard normal for most ancient (1967, above) and most recent (2012, below) DEMs

Table IV summarizes the quality of DEMs for each year. The mean errors (ME) are not null, indicating a small bias in the DEMs. Effectively, dGPS elevations are generally higher than every DEM and there is no spatial structure in this bias. To provide a better estimation of absolute elevation changes between the years, these biases have been removed by adding the mean error to each DEM. 
TABLE IV. DEM precision and accuracy assessment using dGPS survey data

\begin{tabular}{lllllllll}
\hline DEM & 1967 & 1977 & 1983 & 1988 & 1995 & 1999 & 2005 & 2012 \\
\hline ME & 0.315 & 0.504 & 0.281 & 0.296 & 0.541 & 0.493 & 0.453 & 0.356 \\
STD & 0.765 & 0.820 & 0.953 & 0.644 & 0.751 & 0.827 & 0.998 & 0.462 \\
\hline
\end{tabular}

In this study, we are interested in quantifying climate forcing of Alpine landscapes that is, investigation of the possible link between climatic conditions and morphological changes in the landscape. The identification of patterns of erosion and deposition from DEMs of Difference (DoD) is a fundamental aspect in this regard. Moreover, it is necessary to adopt a framework to quantify the confidence that apparent erosion and deposition patterns are real changes and not noise associated with random error in surfaces computed using digital photogrammetry. On the basis of the framework for error analysis proposed by Taylor (1997), Lane et al. (2003) applied an error propagation methodology where the uncertainty in the magnitude of change in the $\mathrm{DoD}$ is determined by the root of the sum in quadrature of the uncertainties associated with each individual DEM:

$$
\sigma_{c}=\sqrt{\sigma_{1}^{2}+\sigma_{2}^{2}}
$$

The standard deviation of error is used here as a measure of uncertainty, but it can be employed to formulate a statistical testing of the significance of each elevation difference $z_{1}-z_{2}$ using a $t$ test (Lane et al., 2003):

$$
t=\frac{z_{1}-z_{2}}{\sqrt{\sigma_{1}^{2}+\sigma_{2}^{2}}}
$$

This equation can be used to threshold the DoD, hence labelling elevation differences within the threshold as noise. With $t=1$, the confidence limit for detection of change is $68 \%$ (Lane et al., 2003). In the research described here, the minimum of level of detection was set with a confidence limit of $90 \%$. This was selected to have greater confidence that a discrepancy is indeed significant and represents real geomorphological change, whilst maintaining enough informative signals in the DoD. Table V summarizes the limit of detection of change (LDC) at this confidence limit for DoD computed between different epochs. The change detection that can be achieved corresponds to \pm 1 to \pm 3 parts per 10,000 of flying height. 
MiCHELETTI et al. Application of archival aerial photogrammetry to quantify climate forcing in high mountain landscapes

TABLE V. Limit of detection of change (LDC) with a confidence limit of $67 \%$ and $90 \%$ computed using the error propagation methods explained above.

\begin{tabular}{ccc}
\hline Year pair & 68\% confidence limit $(m)$ & 90\% confidence limit $(m)$ \\
\hline $2012-2005$ & 1.100 & 1.804 \\
$2005-1999$ & 1.296 & 2.126 \\
$1999-1995$ & 1.118 & 1.833 \\
$1995-1988$ & 0.990 & 1.623 \\
$1988-1983$ & 1.135 & 1.862 \\
$1983-1977$ & 1.244 & 2.040 \\
$1977-1967$ & 1.121 & 1.839 \\
$2012-1988$ & 0.793 & 1.300 \\
$1983-1967$ & 1.208 & 1.981 \\
$2012-1967$ & 0.894 & 1.466 \\
\hline
\end{tabular}

The last operation necessary prior to DoD analysis required an irresolvable aerial photogrammetric issue to be addressed: DEM comparisons in near-vertical rockwalls or forested areas. Steep rock faces and trees can create significant occlusions because of the differences in position of the cameras associated with a particular stereopair. This problem is more apparent towards the edge of any particular image in the pair and stereo-matching processes can be very ineffective in such areas. Only a few matched points representing topographic highs are derived, and interpolation between isolated data points is very unreliable because topographic lows are not present. Accordingly, DoDs will always feature extensive and unrealistic elevation differences in these areas (see example in Fig. 9). A precise reconstruction of these areas is beyond the scope of archival digital applications unless more images of the same date are available; hence a masking procedure was applied here. With the help of orthorectified images, hill-shaded representations, point clouds and $\mathrm{DoD}$, limits of rockwalls and forest boundaries were manually identified and excluded from the datasets.
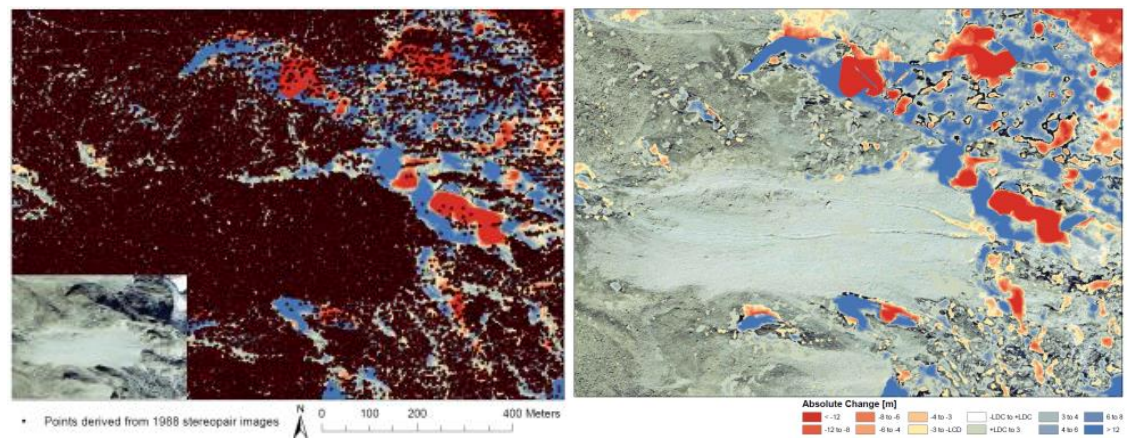

FIG 9. Ineffective stereo-matching in rockwalls (left) for a 1988 stereopair shown by data gaps and consequent unrealistic elevation changes featured in the 20121988 DoD (right, $\mathrm{LDC}=1.30 \mathrm{~m}$ ) 


\section{CLIMATE FORCING AND GEOMORPHIC CHANGES IN ALPINE LANDSCAPES: AN ILLUSTRATION}

Following the methodology presented above, a digital elevation model has been generated for each year available from the 1960s to present and here we illustrate what this yields in terms of our understanding of climate forcing in Alpine landscapes. A reference to the climatic conditions that affect the landscape is necessary for that scope and is provided by mean annual air temperature data (MAAT) for Switzerland since the beginning of the measurement in 1864 as deviation from the reference mean of the period 1961-1990 (Fig. 10, Federal Office of Meteorology and Climatology MeteoSwiss, 2014). Temperature data illustrate that the period of 1967 to 1983 is a period of relative climate stability but that of 1983 to 2012 of relative climate warming.

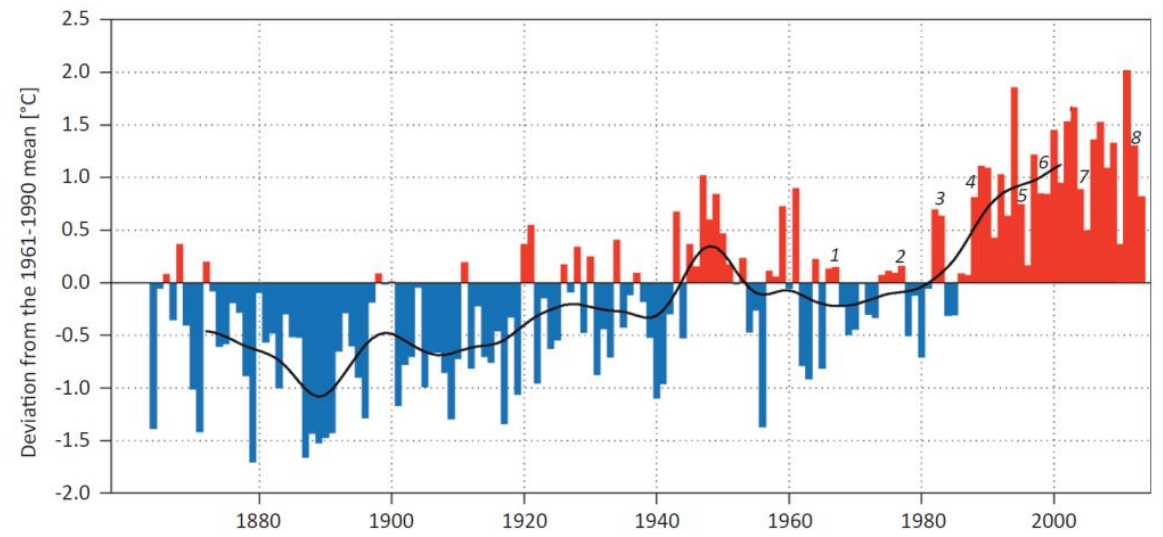

FIG 10. Mean Annual Air Temperatures in Switzerland between 1864 and 2013 as deviation from the reference mean established between 1961 and 1990 (MeteoSwiss, 2014). The black line indicates the twenty-year weighted average (low-pass Gaussian filter). The numbers indicate the year of available aerial imagery.

The interpretation of results is helped by a reference to the spatial assemblage of landforms present; a geomorphological map of the region provided by Maillard et al. (2013) was used for this purpose (Fig 11), allowing the identification of which components of the landscape are most sensitive to both climate cooling and climate warming. The comparison between 1983-1967 and 2012-1988 DoDs is presented in Fig. 11 and illustrates distinct response to warming and stable periods. During the stable/cold period the landscape is very stable, except for glacier and debris-covered-glacier systems that experience a noticeable gain in volume in their upper part; this can be explained by a process of cryogenesis. On the other hand, the period from the mid-1980s to 2012 features enhanced hillslope activity, particularly in rock glaciers, rockslides and debris flow channels. It is apparent that warming climatic conditions caused extensive shrinking of the 
MiCHELETTI et al. Application of archival aerial photogrammetry to quantify climate forcing in high mountain landscapes

glacial systems, especially in the accumulation area and the glacier front zone. Yet, ice ablation is compensated by cold period ice supply in the central part of the Tsarmine glacier (northern area) and at the front of the Tsa glacier (South in the map). These changes aside, perhaps one of the most interesting elements of Fig. 11 is the relative stability of this landscape despite recent climate changes. 

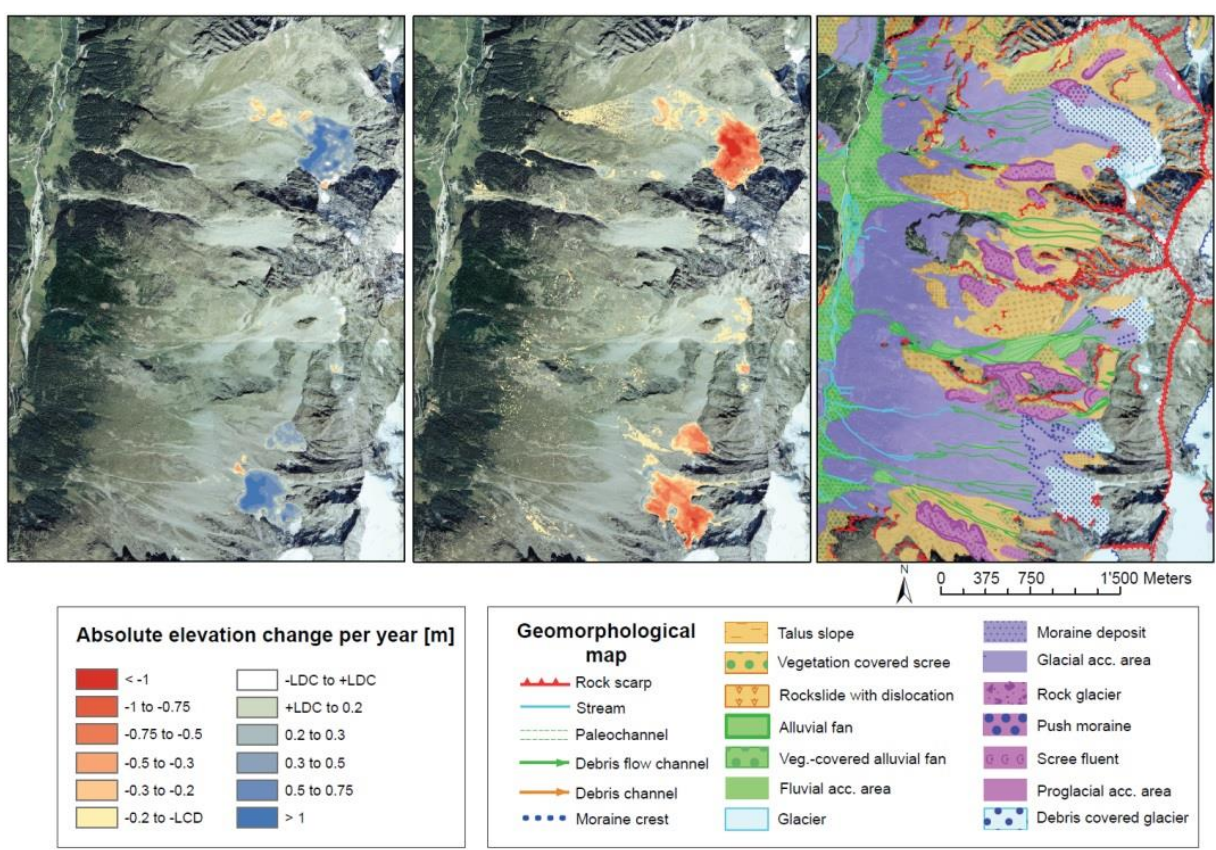

FIG 11. DEMs of Difference comparison between cold period (left, 1983-1967, LCD = $1.981 \mathrm{~m}$ ) and warming period (centre, 2012$1988, \mathrm{LDC}=1.30 \mathrm{~m}$ ) and geomorphological map as a reference to the underlying spatial assemblage of landforms present (right, . A distinct landscape response to both warming and cooling periods is found. The most evident examples include: cryogenesis in glaciers accumulation areas versus glacier retreat, increase in rock glaciers activity under warming conditions. 


\section{CONCLUSION}

In the present research, a complete workflow for the application of archival aerial photogrammetry to quantify geomorphological changes and climate forcing of high mountain landscapes has been proposed. Archival aerial photogrammetry applications remain challenging in Alpine environments for various reasons, including: wide elevation differences, suboptimal quality and varying scale of imagery and the difficulties of establishing ground control. The approach articulated in this study and lessons learned are intended to help geomorphologists work with archival aerial imagery for other sites. Ways to overcome these challenges have been presented, including: techniques to establish appropriate control, conducting careful analysis outcomes at every step and using a conservative approach for error propagation. Accordingly, the paper demonstrates that it is possible to employ archival imagery to obtain high quality DEM data suitable for geomorphological research. Results are encouraging and suggest that even for complex and steep topography the information locked in archival aerial photogrammetry represents a valuable and exploitable resource. It should be stressed that this technique can only observe changes in elevation greater than 11.5 meters using imagery of the scale used here (approximately 1: 20,000). This figure equates well with expected height accuracy of \pm 1 to \pm 3 parts per 10,000 of the flying height at a single epoch, cited in previous work (Fryer et al., 1994). Erosion and deposition patterns that create a vertical signal smaller than this cannot be detected reliably using archival aerial imagery of this scale and historical quality.

\section{ACKNOWLEDGEMENTS}

This research was supported by the Herbette Foundation of the University of Lausanne, the Vaud Canton and the Valais Canton. We would like to thank the University of Fribourg for the collaboration and Christophe Lambiel for providing the geomorphological map used to improve data quality and to interpret the results.

\section{REFERENCES}

Bennett, G. L., Molnar, P., McArdell, B. W., Schlunegger, F. and Burlando, P., 2013. Patterns and controls of sediment production, transfer and yield in the Illgraben. Geomorphology, 188: 68-82.

ChAndler, J. H. and CoOPER, M. 1988. Monitoring the developmends of landslides using archival photography and analytical photogrammetry. Land and Minerals Surveying, 6(11): 576-584.

Chandler, J. H. and MoORE, R. 1989. Analytical photogrammetry: a method for monitoring slope instability. Quarterly Journal Engineering Geology, 22(2): 97-110.

ChAndLer, J. H. and BRUnSDEN, D. 1995. Steady state behaviour of the Black Ven mudslide: the application of archival analytical photogrammetry to studies of landform change. Earth Surface Processes and Landforms, 20(3): 255-275. 
MiCHELETTI $e t$ al. Application of archival aerial photogrammetry to quantify climate forcing in high mountain landscapes

COOPER, M. A. R., 1998. Datums, coordinates and differences. Chapter 2 in Landform monitoring, modelling and analysis (Eds. S. N. Lane, K. S. Richards and J. H. Chandler). Wiley, Chichester. 454 pages: 21-36.

Dewez, T. J. B., Rohmer, J., Regard, V., and CNUdDE, C., 2013 Probabilistic coastal cliff collapse hazard from repeated terrestrial laser surveys: case study from Mesnil Val (Normandy, northern France). Journal of Coastal Research, Special Issue 65, 702-707.

DISSART, O. and JAMET, O. 1995. 3D reconstruction of buildings from stereo-images using both monocular analysis and stereomatching: an assessment within the context of cartographic production. Proceedings of the Society of Photo-Optical Instrument Engineers, 2486: 255-266.

Fischer, L., EISENBeISS, H., KäÄB, A., HugGel, C. and HAEBERLI, W. 2011. Monitoring Topographic Changes in a Periglacial High-mountain Face using High-resulution DTMs, Monte Rosa East Face, Italian Alps. Permafrost and Periglacial Processes, 22(2): 140-152.

Fonstad, M. A., Dietrich, J. T., Courville, B. C., Jensen, J. L. and Carbonneau, P. E. 2013. Topographic structure from motion: a new development in photogrammetric measurement. Earth Surface Processes and Landforms, 38:421-430.

FÖRSTNER, W. 1986. A feature-based correspondence algorithm for image matching. International Archives of the Photogrammetry and Remote Sensing, 26(3): 150-166.

FRYER, J. G., CHANDLER, J. H. and COOPER, M. A. R., 1994. On the accuracy of heighting from aerial photographs and maps: Implications to process modellers. Earth Surface Processes and Landforms, 19: 577-583. doi: 10.1002/esp.3290190609

Gooch, M. J. and ChANDLER, J. H. 2000. Failure prediction in automatically generated digital elevation models. Proceeding of the $4^{\text {th }}$ International Conference on Geocomputation, GeoComputation CD-ROM.

HÖHLE, J., and HÖHLE, M., 2009 Accuracy assessment of digital elevation models by means of robust statistical methods. ISPRS Journal of Photogrammetry and Remote Sensing, 64, 398-406.

INTERGRAPH CORPORATION, 2014. ERDAS HELP IMAGINE. Huntsville, USA

JAMES, M. R. and ROBSON, S. 2014. Mitigating systematic error in topographic models derived from UAV and ground-based image networks. Earth Surface Processes and Landforms, doi: 10.1002/esp.3609.

KäÄB, A. and Vollmer, M., 2000. Surface Geometry, Thickness Changes and Flow Fields on Creeping Mountain Permafrost: Automatic Extraction by Digital Image Analysis. Permafrost and Periglacial Processes, 11: 315-326.

KNIGHT, J., and HARRISON, S., 2013. The impacts of climate change on terrestrial Earth surface systems. Nature Climate Change, 3,24-29.

KNEISEL, C. and KÄÄB, A. 2007. Mountain permafrost dynamics within a recently exposed glacier forefield inferred by a combined geomorphological, geophysical and photogrammetrical approach. Earth Surface Processes and Landforms, 32: 1797-1810.

Leica Geosystems Geospatial Imaging, 2006. Leica Photogrammetry Suite Automatic Terrain Extraction User's Guide. Norcross, USA.

LANE, S. L., ChandLER, J. H. and RichaRDS, K. S. 1994. Developments in monitoring and modelling small-scale river bed topography. Earth Surface Processes and Landforms, 19(4): 349-368.

Lane, S. L., James, T. D. and Crowell, M. D. 2000. Application of digital photogrammetry to complex topography for geomorphological research. Photogrammetric Record, 16(95): 793-821

LANE, S. L., WestawAY, R. M. and Hicks, D. M. 2003. Estimation of erosion and deposition volumes in a large, gravel-bed, braided river using synoptic remote sensing. Earth Surface Processes and Landforms, 28: 249-271.

Lane, S. L., ReID, S. C., Westaway, R. M. and Hicks, D. M. 2004. Remotely sensed topographic data for river channel research: the identification, explanation and management of error. In Spatial Modelling of the Terrestrial Environment, (Eds. R. Kelly, N. Drake, S. Barr), Wiley, Chichester. $157-174$

Lane, S. L., Widdison, P. E., Thomas, R. E., Ashworth, P. J, Best, J. L., Lunt, I. A., Smith, G. H. S. and SimPSON, C. J. 2010. Quantification of braided river channel change using archival digital image analysis. Earth Surface Processes and Landforms, 35(8): 971-985.

Maillard, B., Lambiel, C., Regamey, B., Theler, D. and Reynard, E. 2013. Geomorphological Map of Val d'Hérens, Switzerland. University of Lausanne, Switzerland.

METEOSUISSE, 2014 Climate today: Trends in Switzerland. Tech. rep., www.meteosuisse.admin.ch. 
MiCHELETTI et al. Application of archival aerial photogrammetry to quantify climate forcing in high mountain landscapes

Milledge, D. G., Lane, S. L. and WarbuRTon, J. 2009. The potential of digital filtering of generic topographic data for geomorphological research. Earth Surface Processes and Landforms, 34: 6374.

Remondino, F., Spera, M. G., Nocerino, E., Menna, F. And NeX, F. 2014, State of the art in high density image matching. Photogrammetric Record, 29(146): 144-166. doi: 10.1111/phor.12063

REYNARD, E., LAMBIEL C., and LANE, S. L., 2012. Climate change and integrated analysis of mountain geomorphological systems. Geographica Helvetica, 5-14.

Schwab, M., RiekKe-ZAPP, D., SChNeIDER, H., Liniger, M., SCHLunegger, F., 2008 Landsliding and sediment flux in the Central Swiss Alps: a case study from the Schimbrig landslide, Entlebuch. Geomorphology, 97, 392-406.

Small, R. J., BeECroft, I. R. and StiRling, D. M. 1984. Rates of deposition on lateral moraine embankments, Glacier de Tsidjoure Nouve, Valais, Switzerland. Journal of Glaciology, 30(106): $275-281$.

TAYLOR, J. R., 1997. An introduction to Error Analysis: the Study of Uncertainty in Physical Measurements, second edition. University Science Books: Sausalito, California.

WAlstra, J., DiXON, N. and ChandleR, J. H. 2007. Historical aerial photographs for landslide assessment: two case histories. Quarterly Journal of Engineering Geology and Hydrogeology, 40(4): 315-332.

WELCH, R. and JORDAN, T. R. 1983. Analytical non-metric close-range photogrammetry for monitoring stream channel erosion. Photogrammetric Engineering \& Remote Sensing, 49(3): 367374.

WiCKENS, E. and BARTON, N. R. 1971. The application of photogrammetry to the stability of excavated rock slopes. Photogrammetric Record, 7(37): 46-54.

Wolf, P. R. 1983. Elements of photogrammetry. Second edition. Mc Graw Hill, New York. 628

pages. 